\title{
APLICAÇÃO DO MÉTODO AHP NA TOMADA DE DECISÃO PARA A REDUÇÃO DOS NÍVEIS DE AÇÃO LEGAL EM TELECOMUNICAÇÕES
}

\author{
APPLICATION OF ANALYTIC HIERARCHY PROCESS (AHP) METHOD IN \\ DECISION MAKING FOR REDUCTION OF THE LEVELS OF LEGAL ACTION IN \\ TELECOMMUNICATIONS
}

\section{Rodrigo Araújo Pereira}

Mestre em Engenharia Elétrica pela Pontifícia Universidade Católica de Campinas- PUC /Campinas

E-mail: rodrig053@globo.com (Brasil)

\section{David Bianchini}

Doutor em Educação pela Universidade Estadual de Campinas - UNICAMP Professor da Pontifícia Universidade Católica de Campinas, PUC Campinas E-mail: davidb@ puc-campinas.edu.br (Brasil) 


\title{
APLICAÇÃO DO MÉTODO AHP NA TOMADA DE DECISÃO PARA A REDUÇÃO DOS NÍVEIS DE AÇÃO LEGAL EM TELECOMUNICAÇÕES
}

\section{RESUMO}

Este artigo tem como objetivo analisar o nível de insatisfação do cliente das empresas de telefonias móveis no Brasil, pois existem muitas reclamações desse setor junto a Fundação de Proteção e Defesa do Consumidor - PROCON. Tais fatores afetam a imagem corporativa da empresa, reduzindo sua competitividade em relação à concorrência. Optou-se por utilizar o Analytic Hierarchy Process - AHP para lidar com o problema que incidiu sobre a hipótese de a possibilidade de reduzir os níveis de processos na indústria de telefonia móvel. Após a aplicação da AHP para a solução proposta, os resultados foram apresentados na seguinte ordem de prioridade das alternativas com preferência a ser trabalhado no momento imediato: Carrega importância indevida com a taxa de reprovação de 27,94\% com importância de serviço em $23,80 \%$, a qualidade do serviço com $22,42 \%$ de importância, Bloqueio em 11,7\%, o atraso na entrega com $9,97 \%$ e 4,17\% com publicidade enganosa em importância. Identificados os valores apropriados para cada um dos problemas responsáveis por reclamações ao PROCON, cabendo às organizações de telefonia móvel analisar cada um destes problemas, identificando suas respectivas causas.

Palavras-chave: Método AHP; Problemas de Mobile; Análise Multivariada, Análise Hierárquica, Tomada de Decisão.

\section{APPLICATION OF ANALYTIC HIERARCHY PROCESS (AHP) METHOD IN DECISION MAKING FOR REDUCTION OF THE LEVELS OF LEGAL ACTION IN TELECOMMUNICATIONS}

\begin{abstract}
This work had the purpose to analyze the level of dissatisfaction of the client for mobile telephone companies in Brazil. These companies are the greatest cause of complaints to the organizations of consumer protection. Dissatisfaction affects the company's corporate image, thus reducing its competitiveness. The study uses the Analytic Hierarchy Process (AHP) to assess the possibility of reducing levels of lawsuits in the mobile ind ustry. After applying the AHP to the complaints, the results were presented in the following order of priority of need for immediate change: Sense of Undue Importance (27.94\% failure rate), Service (23.80\%), Service Quality (22.42\%), Line Blocking (11.7\%), Delay in Delivery (9.97\%) and Misleading Advertising (4.17\%). With these reasons of complaints logged with the consumer protection agency identified, it is now mobile organizations responsibility to analyze each of these problems to identify their causes.
\end{abstract}

Keywords: AHP method; Problems of Mobile; Multivariate Analysis, Analytic Hierarchy Process, Decision Making.

REMark - Revista Brasileira de Marketing, São Paulo, v. 12, n. 4, p. 153-182, out./dez. 2013. 


\section{INTRODUÇÃO}

A tomada de decisão é crucial para as empresas que convivem mediante cenário de grande competitividade, pois uma decisão tomada de forma errada pode significar uma perda de milhares de dólares é justamente para evitar este acontecimento e auxiliar os tomadores de decisões que surgiu o método MCDM - Multiple Criteria Decision Making, assim as decisões podem ser tomadas com maior precisão.

O atual cenário de forte competitividade em que vive as empresas do setor de telefonias móveis e o aumento da exigência por parte dos clientes é notável, também é notável que as empresas do setor trabalhem com margens de lucros reduzidas.

Este artigo tem a finalidade de estudar a aplicação de um método de apoio à decisão aplicada na intenção de reduzir os níveis de ações judiciais em empresas do setor de telefonias móveis, identificando quais atributos é tido como responsáveis pelas reclamações que geram essas ações judiciais.

Tem-se como finalidade especifica através da aplicação do método AHP identificar o grau de desempenho e importância relativa entre os atributos para que o fato possa ser tratado com uma maior precisão. A utilização do método de apoio à decisão visa aumentar a transparência e a eficiência nestes processos de tomada de decisão.

Mediante a algumas pesquisas realizadas atra vés do Órgão de Defesa do Consumidor (PROCON) e a Agência Nacional de Telecomunicações (ANATEL), foi possível identificar que as empresas de telefonia celular são as campeãs em reclamações e juntas somam multas que ultrapassam o valor de $\mathrm{R} \$ 3.192 .300,00$.

Este trabalho tem como propósito problemático investigar o que ocasionam essas multas com valores exorbitantes, identificando os índices prioritários de reclamações dos clientes para que possam ser tratados. Com a aplicação do método AHP seria possível a identificação dos índices prioritários de reclamação?

Este trabalho busca dar sua contribuição para o meio empresarial, social e acadêmico, pois em um setor de alta competitividade como se encontra o setor de telefonias moveis, torna-se possível a empresa obter um maior resultado nos lucros, um aumento no número de clientes com a melhoria da qualidade dos serviços prestados e uma valorização na marca da empresa.

O trabalho torna-se relevante não apenas pelos valores envolvidos, mas também pelos desafios identificados, pelos executivos das empresas que explicitam a necessidade de redução dos custos para que a empresa venha obter uma maior lucratividade e aderir a novos investimentos até mesmo em outras áreas do segmento.

REMark - Revista Brasileira de Marketing, São Paulo, v. 12, n. 4, p. 153-182, out./dez. 2013. 
$\mathrm{Na}$ área acadêmica ainda são poucos os estudos aprofundados sobre o assunto, e espera-se que este trabalho contribua com referencial teórico e analítico.

\section{O SETOR DE TELECOMUNICAÇÕES}

Com a quebra do monopólio em 1995, deu-se início a reestruturação do setor de telecomunicações brasileiro e telefonia celular. Seguindo-se, em 1997, a promulgação da Lei Geral de Telecomunicações - LGT (n.9.472/97) e a criação da ANATEL, configurando-se, então, a privatização das empresas do setor em 1998 e começo da competitividade entre as operadoras. A reestruturação no setor de telecomunicações teve como objetivos principais a instalação de uma infra-estrutura moderna de telecomunicações e a diminuição do espaço entre oferta e demanda dos serviços existentes no mercado nacional.

Diante do marco regulatório e atuação da agência reguladora, empresas do mundo inteiro que atuavam no setor investiram no país, assim, dando-se início à competição no setor. Segundo Frontini (2008, p. 54), desde 1998, é vertiginoso o crescimento da base instalada de acessos fixos e móveis no país, condizente com a busca de ganhos de escala características do setor, que requer elevados investimentos e necessita de ganhos de escala para rentabilizar os ativos.

Hoje, o setor se encontra em um novo momento, no qual se busca a rentabilidade dos ativos para remunerar seus acionistas e assegurar a sobrevida das empresas. Neste cenário, a estratégia tem um papel fundamental para as empresas do setor (FRONTINI, 2008).

\subsection{DOS NÍVEIS DE RECLAMAÇÕES E DANOS JUDICIAIS : PROCON/ANATEL}

Os assuntos ligados aos interesses e direitos do consumidor se revelam como temas de relevada importância. Verifica-se, de fato, uma maior consciência da sociedade em relação aos direitos contratados. E tal quadro é bem significativo quando se refere ao setor de telecomunicações. Na realidade, os clientes deste serviço estão cada vez mais atentos aos critérios e condições de contrato. (Revista PROCON-SP, 2010)

A sociedade moderna é, nitidamente, uma sociedade de consumo. Os processos de consumo, por sua vez, necessitam de princípios claros e objetivos ligados aos direitos e deveres na relação entre fornecedor e consumidor. Portanto, as questões legais envolvidas nesse processo merecem estudo próprio. (Revista PROCON-SP, 2010)

REMark - Revista Brasileira de Marketing, São Paulo, v. 12, n. 4, p. 153-182, out./dez. 2013. 
A importância da divulgação da legislação de defesa do consumidor para a população em geral torna, em especial, o usuário/consumidor ciente de seus direitos e otimiza a aplicação efetiva da lei, sobretudo do Código de Defesa do Consumidor. Realmente, espera-se que os efeitos da utilização em totalidade dessa legislação possam contribuir, de maneira efetiva, para a perfeita assimilação, pela sociedade brasileira, do conceito de cidadania - ideal colimado pelo código. (Revista PROCON-SP, 2010)

Anteriormente à promulgação de mecanismos legais próprios ao direito do consumidor, os casos tratados pelo Código Civil não poderiam atribuir uma igualdade entre as partes. Isto quer dizer que o vendedor de um bem, segundo o Código Civil, podia livremente impor as regras, ditar as cláusulas contratuais que estariam consubstanciadas em um contrato de consumo. Tais contratos eram regulados pelo Código Civil, fundado, em sua maior parte, em normas dispositivas, ou seja, normas que podem ser livremente derrogadas pelas partes. (Revista PROCON-SP, 2010)

Dessa forma, por exigência do moderno consumidor, a respectiva legislação foi revista e atualizada, sendo sua base o Código de Defesa ao Consumidor. Sob essa ótica, cumpre esclarecer que as relações entre cliente e operadoras de telefonia estão construindo interesses coletivos traduzidos por relações de massa. Importa, então, entender a crescente necessidade de tutela dos interesses difusos, coletivos e de categorias. (Revista PROCON-SP, 2010)

Nessa seara, posiciona-se o PROCON como órgão gestor e fiscalizador. Ocorre que, segundo Gurgoni (2010), os serviços de telecomunicações apresentam elevado índice de reclamações. Conforme informa o autor, no ano de 2009, no registro de reclamações nas sedes do PROCON, de dez queixas, pelo menos seis eram referentes ao setor de telefonia.

Nesse sentido, é importante reconhecer, em relação à conseqüências e danos judiciais, que, nas relações de massa, é muito difícil reparar adequadamente os danos causados aos consumidores. Medidas compensatórias, além de serem lentas, não abrangem todos os cidadãos. Essa é a razão pela qual os países econômica e socialmente desenvolvidos estabeleceram um controle doutrinário da situação. Esse controle se destina, justamente, a evitar a consumação do prejuízo. Nos casos de "apagão", os consumidores devem reivindicar prejuízos considerando danos materiais e não-materiais em face da cessação do fornecimento do serviço. (Revista PROCON-SP, 2010)

REMark - Revista Brasileira de Marketing, São Paulo, v. 12, n. 4, p. 153-182, out./dez. 2013. 


\section{MÉTODO AHP}

O método AHP foi definido como a ferramenta de apoio a este trabalho pela necessidade da realização de análise em um cenário complexo. As problemáticas para tomada de decisão podem ser classificadas como não-estruturadas (nível estratégico) e com múltiplos critérios (quantitativos ou qualitativos).

O método AHP se trata de uma ferramenta proposta por Thomas L. S. da Universidade da Pensilvânia, na década 1970, cujo objetivo é reproduzir o raciocínio humano na comparação de elementos, é uma ferramenta utilizada para o auxílio à tomada de decisões. A comparação acontece através de uma ordenação dos itens em questão de acordo com o nível de importância e dos atributos (SILVA; CABRERA; TEIXEIRA, 2006). O AHP foi um dos primeiros métodos criados para facilitar o processo de tomada de decisão através dos múltiplos critérios (quantitativos ou qualitativos).

Critérios são atributos que podem ser quantificados ou avaliados e que contribuem para a decisão. A busca da solução de um problema freqüentemente ocorre em ambiente onde os critérios são conflitantes, ou seja, onde o ganho de um critério poderá causar uma perda em outro. Estes critérios podem ser do tipo fator, compostos por variáveis que acentuam ou diminuem a aptidão de uma determinada alternativa para o objetivo em causa ou podem ser do tipo exclusão, variáveis que limitam as alternativas em consideração na análise, excluindo-as do conjunto solução (ZAMBON et al., 2005, p. 03).

Segundo Rafaeli e Müller (2007), um dos pontos de maior dificuldade enfrentado pelas empresas é ponderar de forma qualitativa como uma unidade de análise está cumprindo suas metas. Verifica-se que os indicadores disponibilizados pelas unidades são atualizados e analisados constantemente, mas quanto maior o número de indicadores maior o grau de dificuldade em uma avaliação de desempenho.

\subsection{JUSTIFICATIVA PARA ESCOLHA DO MÉTODO}

Trabalhar com medida de desempenho nem sempre é uma tarefa simples, pois muitas vezes os dados não estarão disponíveis, acessíveis ou estruturados no modo ideal para realizar o trabalho. Devem ser considerados também os aspectos subjetivos, onde as medidas são complexas, pelo fato de ser de caráter pessoal e de difícil externalização.

O fundamento da relação do método AHP é a decomposição e síntese entre os critérios até chegar à priorização das indicações e com isso obter o melhor resultado de medição. (SAATY, 1991)

REMark - Revista Brasileira de Marketing, São Paulo, v. 12, n. 4, p. 153-182, out./dez. 2013. 
Em diferentes tipos de situações para tomada de decisões, esta envolvida seleções de alternativas e critérios. Porém, os tomadores de decisões têm pontos conflitantes e diferença de juízos de valores.

Os métodos de decisão múltiplos critérios surgem como uma alternativa para solução deste problema. Os métodos de decisão de múltiplos critérios é uma técnica que pode ser utilizado para:

1. Identificar a melhor opção;

2. Ordenar as opções;

3. Gerar um número limitado de alternativas para uma subseqüente avaliação;

4. Distinguir as possibilidades aceitáveis das não aceitáveis;

Devido à quantidade de opções em métodos multicritério para tomada de decisão e da diversidade de características que cada um dos métodos possui, tornou-se crucial para o desenvolvimento desta pesquisa selecionar aquele que melhor se encaixe nesta pesquisa.

Após uma comparação realizada por SALOMON (2010) com outros modelos de ferramentas para tomada de decisão multicritério, na qual os resultados obtidos por diferentes métodos foram considerados similares e diversas vantagens da aplicação do AHP foram observadas em todos os casos, recomenda-se a utilização do AHP para a obtenção de bons resultados, mesmo quando as alternativas e critérios de decisão não estão diretamente relacionados ou não são totalmente independentes.

O método AHP é o mais adequado para esta pesquisa, pois ele tem diversos atributos desejáveis para a realização do trabalho mostrado na Figura 1 por Gomes (2009), tais como: a) é um processo de decisão estruturado que pode ser documentado e repetido; b) é aplicável a situações que envolvem julgamentos subjetivos; c) utiliza tanto dados quantitativos como qualitativos; d) provê medidas de consistência das preferências; e) há uma ampla documenta sobre suas aplicações práticas na literatura acadêmica; f) seu uso é apropriado para grupos de decisão.

REMark - Revista Brasileira de Marketing, São Paulo, v. 12, n. 4, p. 153-182, out./dez. 2013. 


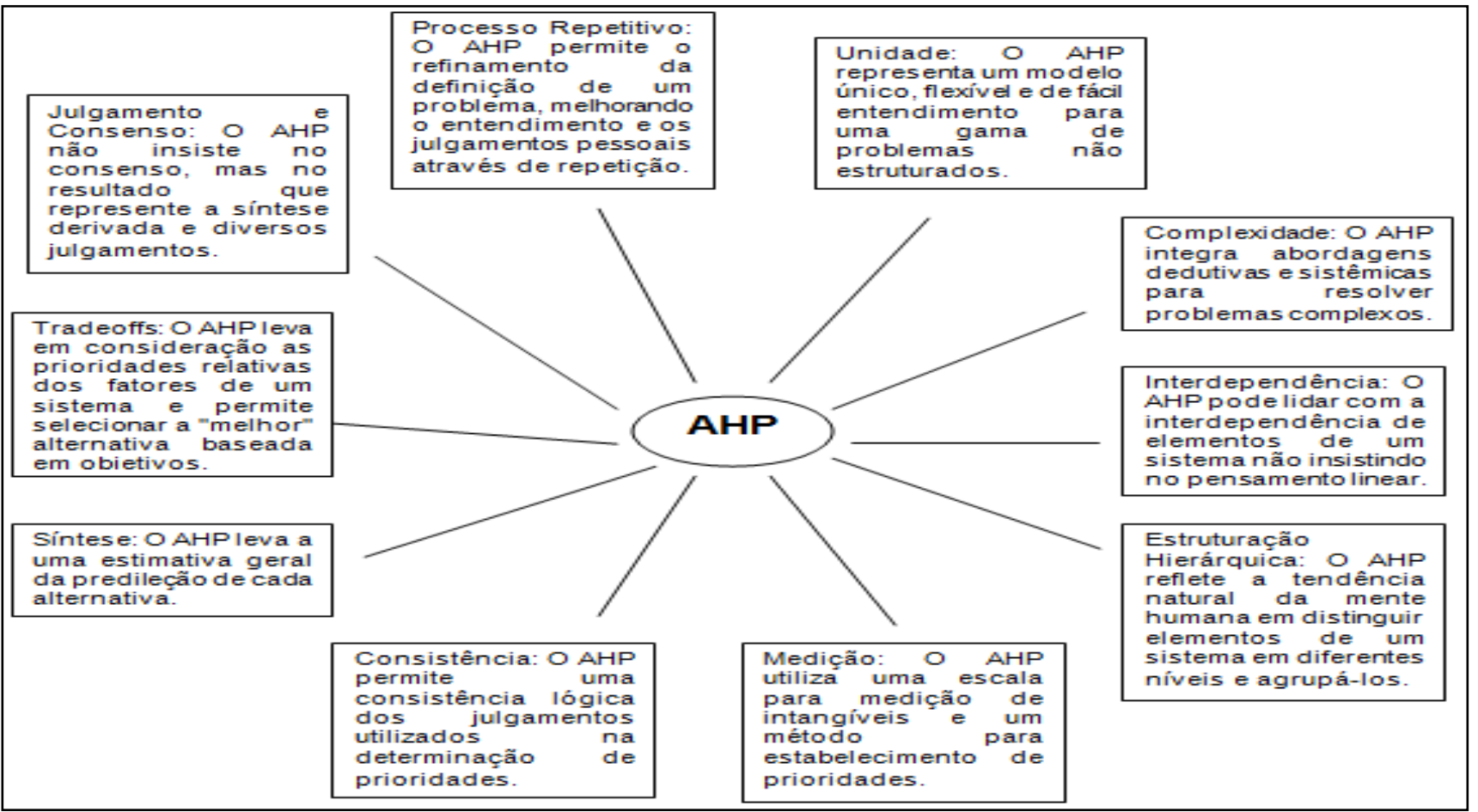

Figura 1 - Flexibilidade do Modelo AHP

Fonte: (GOMES 2009, p. 77)

Algumas características benéficas do método AHP são apresentadas em (GOODWIN, 2004),

- A estruturação formal dos problemas que necessitem de escolhas ou julgamentos permite que problemas complexos possam ser decompostos em conjuntos de julgamentos mais simples, e oferece uma razão documentada para a escolha ou priorização de uma determinada opção em detrimento a outras.

- A simplicidade da comparação entre pares de alternativas significa que o julgador pode focar uma pequena parte do problema por vez, simplificando a sua tarefa. As comparações verbais também são importantes aos julgadores que poderiam ter dificuldades em expressar suas opiniões numericamente.

- A redundância de julgamentos permite que a consistência do julgamento seja verificada, e é considerada uma boa prática a obtenção das entradas para um modelo de decisão de diferentes formas. Com a utilização do AHP isto é feito de maneira automática.

- A versatilidade do AHP é evidenciada pelos diferentes tipos de aplicação inclusive envolvendo incertezas e previsões.

REMark - Revista Brasileira de Marketing, São Paulo, v. 12, n. 4, p. 153-182, out./dez. 2013. 


\section{METODOLOGIA DE PESQUISA}

Nesta fase será definido onde e como a pesquisa acontecerá. É definido o tipo de pesquisa, limitações, a população (universo da pesquisa), amostragem, instrumentos de coleta de dados e a forma de como será tabulado e analisado os dados colhidos. Todas as fases identificadas e as orientações realizadas deverão servir de guia para elaboração desta pesquisa.

\subsection{LIMITAÇÕES DO ESTUDO}

Não obstante a pesquisa ser um estudo de caso único, alguns aspectos referentes às suas limitações são importantes de serem colocados.

Primeiramente o setor escolhido para a pesquisa empírica, o de telecomunicações em caráter específico telefonia móvel, é um setor muito problemático devido a diversos de fatores conjunturais e até mesmo estruturais do país. Se a pesquisa abarcasse todos eles, tanto ao nível quantitativo como qualitativo, com certeza seria um estudo interminável, até porque o objetivo deste artigo não era esse.

Outra limitação do estudo diz respeito à impossibilidade de se generalizar o caso em foco para todo o setor. Dois são os fatores determinantes: o primeiro, por se tratar de uma pesquisa exploratória; o segundo, pela especificidade do tema/assunto escolhido como pesquisa. A generalização das mudanças e adaptações estratégicas que ocorreram em uma dada organização ao longo de um período de tempo é uma situação complexa, ou mesmo, impossível de ser operacionalizada. O que se poderia propor é um estudo multicaso, com isso seria possível comparar os dados para a busca de outras conclusões. Porém, não é a real situação desta pesquisa, pois aqui foi apenas estudado um único caso e em profundidade.

\subsection{CARACTERIZAÇÃO DA PESQUISA}

Toda pesquisa bibliográfica é demonstrada com conceitos, definições e estudos sobre Avaliação de Desempenho, Tomada de Decisão, MCDA e sobre o Método AHP. Segundo SILVA e MENEZES (2001, p. 21): Pesquisa Bibliográfica: quando elaborada a partir de material já publicado, constituído principalmente de livros, artigos de periódicos e atualmente com material disponibilizado na Internet.

Para realização deste estudo, mostra-se de forma mais adequada à aplicação da metodologia da pesquisa exploratória.

REMark - Revista Brasileira de Marketing, São Paulo, v. 12, n. 4, p. 153-182, out./dez. 2013. 
De acordo com (PIOVESAN e TEMPORINI, 1995), Uma pesquisa exploratória pode ser realizada de três formas: (1) mostrar um entendimento melhor ao pesquisador sobre uma situação, (2) aplicar a prática de um método em estudo, (3) desenvolver um método que poderá ser aplicado.

Define-se pesquisa exploratória, na qualidade de parte integrante da pesquisa principal, como o estudo preliminar realizado com a finalidade de melhor adequar o instrumento de medida à realidade que se pretende conhecer. Em outras palavras, a pesquisa exploratória, ou estudo exploratório, tem por objetivo conhecer a variável de estudo tal como se apresenta, seu significado e o contexto onde ela se insere. A pesquisa exploratória tem por finalidade o refinamento dos dados da pesquisa e o desenvolvimento e apuro das hipóteses, nesta nova concepção é realizado com a finalidade precípua de corrigir o viés do pesquisador e, assim, aumentar o grau de objetividade da própria pesquisa, tornando-a mais consentânea com a realidade. (PIOVESAN e TEMPORINI, 1995, p. 321).

Portando, uma pesquisa cientifica seria a realização concreta de uma investigação planejada e desenvolvida de acordo com as normas estabelecidas pela metodologia cientifica. A metodologia cientifica é entendida como um conjunto de fases ordenadamente colocado que você deve vencer na investigação de um fenômeno. Isso inclui: escolha do tema, planejamento, desenvolvimento, coleta e a tabulação de dados, análise dos resultados, realização das conclusões e a publicação dos resultados. (SILVA e MENEZES, 2001)

\subsection{POPULAÇÃO E AMOSTRA}

O universo da pesquisa centra-se no setor de telefonias moveis e a amostra é composta por dados colhidos através do site RECLAMEAQUI, a amostra foi selecionada através do ranking de empresas mais reclamadas no site RECLAMEAQUI.

O site RECLAMEAQUI foi selecionado como fonte fornecedora dos dados, pois segundo pesquisas realizadas no inicio de 2013 pela empresa e-Life (PROXXIMA, 2013), empresa especializada no monitoramento de marcas na internet, e pesquisa apresentada no Portal da Revista Exame, o site RECLAMEAQUI Consumidor, lançado em 2001, onde em 2012 chegou a 3.7 milhões reclamações postadas ${ }^{1}$ e mais de 3.6 milhões de usuários cadastrados ${ }^{2}$ já é um dos maiores site do Brasil que mais recebe comentários de usuários sobre empresas, ficando atrás apenas do FACEBOOK, TWITTER, BLOGSPOT, WORDPRESS (SILVA e PAIVA, 2009; E-

\footnotetext{
${ }^{1} \mathrm{http}: / /$ merececo mentario.co m/2013/03/o-sucesso-do-site-reclame-aqui/

${ }^{2} \mathrm{http}$ ://www.estadao.com.br/noticias/impres so,recla me-aqui-a mplia-servicos-a-e mpres as, $616822,0 . \mathrm{ht} \mathrm{m}$
}

REMark - Revista Brasileira de Marketing, São Paulo, v. 12, n. 4, p. 153-182, out./dez. 2013. 
LIFE, 2013). E este número só tende a aumentar com a expansão do mobile e o surgimento de novos aplicativos de atendimento (E-LIFE, 2013).

O RECLAMEAQUI considera-se um site que ganhou o espaço dos órgãos de defesa do consumidor, devido ao retorno obtido por esse meio ser bem mais satisfatório para os consumidores do que pelo meio convencional, pois enquanto o PROCON estabelece um prazo de retorno para as empresas entre 100 dias e muitas vezes não resultando uma solução, o RECLAMEAQUI tem uma média de três dias para resposta. (SILVA e PAIVA, 2009)

\subsection{PROCEDIMENTOS DE COLETA DE DADOS}

A coleta de dados será executada por meio de coleta de informações referente a reclamações de clientes que foram realizadas no site www.reclameaqui.com.br

Para a realização desta análise foram coletados dados 3615 reclamações relativos aos meses de julho, agosto, setembro e outubro de 2010 sendo avaliada a evolução de CAD destes problemas neste período, qual pode ser visualizada nos anexos posteriormente. Na Figura 4 podese perceber a quantidade total de reclamações apresentadas neste período, na qual se pode perceber o impacto de cada tipo de problemas sobre a imagem da organização.

A aplicação do método AHP no trabalho será realizada conforme a Figura 2 adaptada de Souza (2003), onde é possível a visualização do fluxo das atividades a serem realizadas. A pesquisa-ação é caracterizada pela interação com os atores na definição do problema a ser estudado, no planejamento e na busca pela solução do problema na pesquisa. Destaca-se como uma característica bastante forte na pesquisa-ação é a possibilidade de redirecionamento do trabalho, conforme o desenvolvimento do trabalho. A partir deste ponto é possível notar a semelhança existente entre a pesquisa-ação e o Ciclo PDCA.

REMark - Revista Brasileira de Marketing, São Paulo, v. 12, n. 4, p. 153-182, out./dez. 2013. 


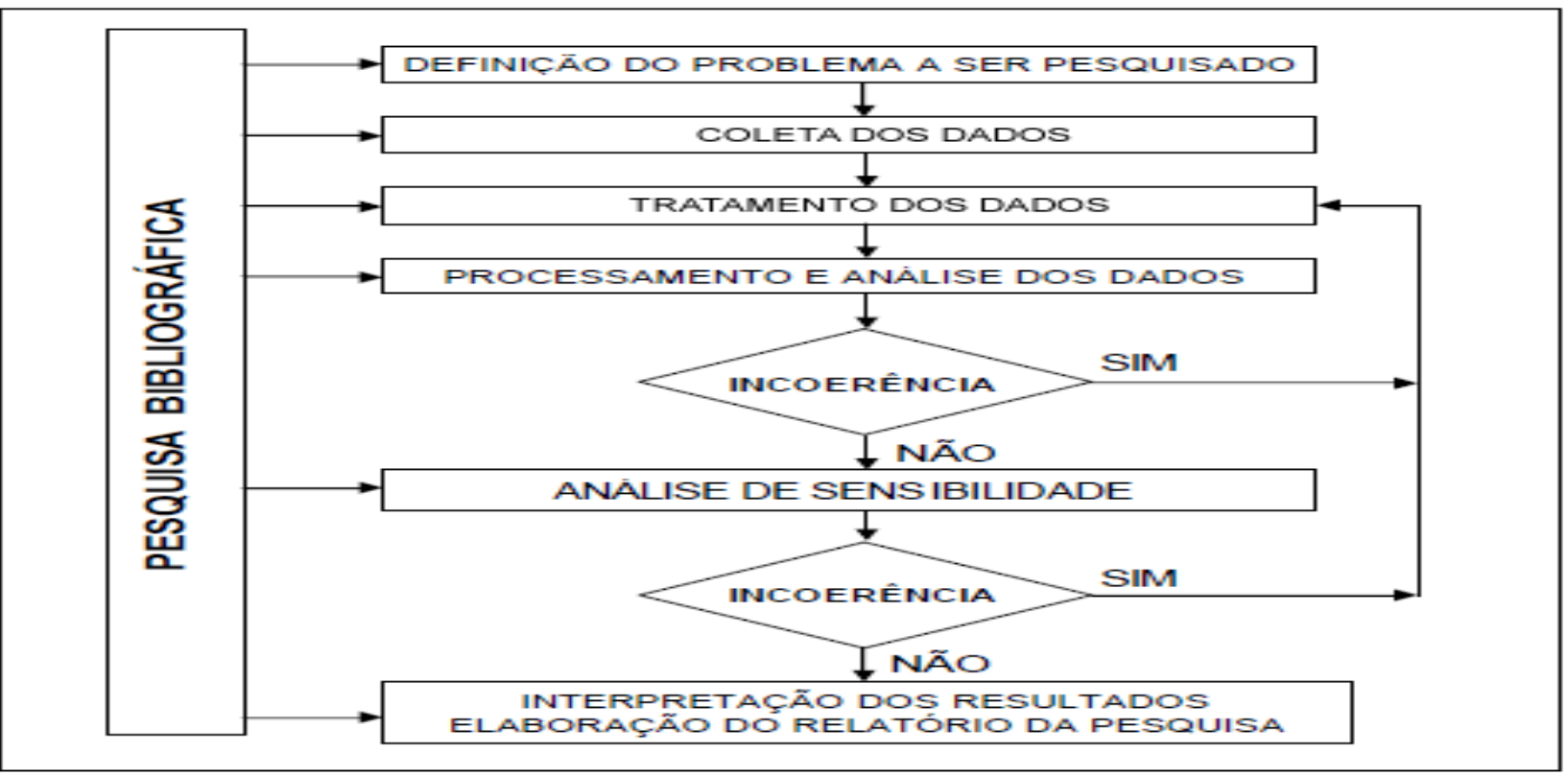

Figura 2 - Fluxo das Atividades da Pesquisa-Ação com o Método AHP

Fonte: (Adaptado de SOUZA, 2003)

\subsection{INSTRUMENTOS DE MEDIDAS UTILIZADOS}

Diversos autores na literatura desenvolveram estudos sobre o assunto, dentre eles podemos destacar SALOMON e MONTEVECHI (2001) onde apresenta comparações realizadas por ZANAKIS (1998) comparações entre o AHP, TOPSIS e ELECTRE. Ainda SALOMON et al. (1999; 2010) pode concluir em uma pesquisa onde comparou o método AHP com FDA, MACBETH, TOPSIS e ANP que em nenhum momento o AHP é inferior a qualquer outro método de decisão multicritério e mediante aos resultados é possível notar que foram considerados similares e diversas vantagens da aplicação do AHP podem ser constatadas em todos os casos. E por fim SALOMON ainda recomenda a utilização do método AHP para obtenção de bons, senão ótimos resultados. Saunders (2010) em uma análise técnica entre os métodos SJT, MAUT, AHP e PA aponta o método AHP uma tecnologia claramente superior.

SALOMON (2010) realiza uma comparação em sua tese de livre docência entre os métodos (MCDM) AHP e MACBETH e através do estudo comprovou-se de fato que o AHP é o melhor método para tomada de decisão multicritério, pois através das comparações realizadas o método MACBETH gerou dois resultados incorretos, enquanto o método AHP gerou resultados totalmente validos.

Já GUGLIELMENTTI, MARINS e SALOMON (2003) em um trabalho de mapeamento profundo dos métodos de decisão identificarão pontos e características importantes, mostrando os

REMark - Revista Brasileira de Marketing, São Paulo, v. 12, n. 4, p. 153-182, out./dez. 2013. 
principais pontos fortes e fracos de cada um dos métodos testado, facilitando a escolha dos usuários em relação a qual método utilizarem em cada situação, conforme é notável na Tabela 1 de Gugliametti, Marins e Salomon, (2003).

Tabela 1 - Comparação teórica entre métodos de MCDM

\begin{tabular}{|c|c|c|c|}
\hline & \\
\hline & AHP & МАНР & ELECTRE \\
\hline \multicolumn{4}{|c|}{ ENTRADA DOS DADOS (INPUT) } \\
\hline Utilização em decisões com vários níveis & SIM & SIM & NÃO \\
\hline Restrições quanto à quantidade de elementos em um nível & SIM & NÃO & NÃO \\
\hline Restrições quanto à quantidade de elementos em u m nível & ALTA & $\begin{array}{c}\text { MÉDIA A } \\
\text { ALTA }\end{array}$ & BAIXA \\
\hline Necessidade de processar os dados antes que estes possamser usados & $\mathrm{NÃO}$ & SIM & SIM \\
\hline Possibilidade de tratar dados quantitativos e qualitativos & SIM & SIM & SIM \\
\hline Possibilidade de lidar com proble mas do tipo técnico & SIM & SIM & SIM \\
\hline Possibilidade de tratar critérios/alternativas dependentes & NÃO & NÃO & NÃO \\
\hline Possibilidade de criar as escalas de julgamento de acordo com o contexto & $\mathrm{NÃO}$ & SIM & NÃO \\
\hline \multicolumn{4}{|c|}{ SAIDA DOS DADOS (OUTPUT) } \\
\hline Proble mas com a locação em conjuntos & $\mathrm{NA} O$ & $\mathrm{NÃO}$ & NÃO \\
\hline Proble mas com avaliação de des empenho & SIM & SIM & $\mathrm{NA} O$ \\
\hline Proble mas com avaliação de desempenho em classes & NÃO & $\mathrm{NA} O$ & $\mathrm{NA} \mathrm{O}$ \\
\hline Proble mas com avaliação de desempenho em classes & SIM & SIM & NÃO \\
\hline Proporciona soluções mu ito refinadas & SIM & SIM & NÃO \\
\hline Proporciona somente eliminação de algumas alternativas & $\mathrm{NA} O$ & NÃO & SIM \\
\hline Permite a avaliação de coerência dos julgamentos & SIM & $\mathrm{NÃO}$ & $\mathrm{NÃO}$ \\
\hline \multicolumn{4}{|c|}{ INTERFACE TOMADOR DE DECIS ÃO Versus MÉTODO } \\
\hline Disponibilidade de software para download gratuito & SIM & NÃO & NÃO \\
\hline Necessidade de um especialista no método utilizado & MÉDIA & ALTA & MÉDIA \\
\hline Utilização de decisões em grupo & SIM & SIM & NÃO \\
\hline Permissão para a participação de mais de u ma pessoa na decisão & SIM & SIM & SIM \\
\hline Facilidade para estruturar o problema & ALTA & MÉDIA & N/A \\
\hline Possibilita o aprendizado sobre a estrutura do problema & SIM & SIM & N/A \\
\hline Nível de co mpreensão conceitual e detalhada do modelo e algorit mo & ALTO & MÉDIA & BAIXO \\
\hline Nível de co mpreensão para o decisor referente à forma de trabalho & ALTO & ALTO & BAIXO \\
\hline Transparência no processamento e nos resultados & ALTA & BAIXA & MÉDIA \\
\hline Quantidade de aplicações práticas & ALTA & BAIXA & BAIXA \\
\hline Nú mero de publicações científicas & ALTA & BAIXA & MÉDIA \\
\hline
\end{tabular}

Fonte: (GUGLIELMETTI, MARINS e SALOMON, 2003) 
Na aplicação em decisões de vários níveis, nota-se que os métodos AHP e MAHP possuem metodologias específicas para composição e resolução dos problemas com hierarquias profundas. Já com o ELECTRE não foram encontrados artigos que abrangessem o assunto de hierarquias com diversos níveis. (GUGLIELMETTI, MARINS e SALOMON, 2003)

De acordo com GUGLIELMETTI, MARINS e SALOMON, (2003), Analisando a quantidade de alternativas e critérios, constatou-se que o único método que apresenta alguma restrição é o AHP original. Baseado em Miller (1956), Saaty (1997) propôs a comparação com no máximo nove itens simultaneamente, problema o qual foi corrigido por Saaty com a aplicação do ratings.

Saaty (2006 e 2008) e Saloman et al.. (2009) comenta que a diferença na aplicação do ratings é que permite estabelecer comparações com mais do que nove níveis de importância ou desempenho, porque ele trabalha com medição absoluta (neste caso as alternativas são comparadas de acordo com os níveis de intensidade associados a cada critério/subcritério).

O MAHP e o ELECTRE oferecem grande dificuldade adicional, pois na aplicação do algoritmo torna-se necessário que seja feito um processamento preliminar dos dados quantitativos. No ELECTRE é necessária a transformação dos valores cardinais em ordinais e no MAHP é necessária a transformação para escala geométrica, na Tabela 2 de Alves (2007) é possível notar a comparação dos critérios relevantes de cada método. (GUGLIELMETTI, MARINS e SALOMON, 2003). O MAHP enfrente dificuldades para implementação do algoritmo, pois é necessário que seja realizado um processamento dos dados quantitativos, pois o tomador de decisão pode inferir no resultado.

Já o ELECTRE tem grandes dificuldades ao tentar ou comparar duas alternativas por falta de informação ou excesso de subjetividade por parte do tomador de decisão e com isso gera imprecisão no resultado, outro problema enfrentado pelo método é relacionado ao número de parâmetros presentes em seu desenvolvimento, o que torna o método muito complexo e difícil de ser aplicado. (ALVES, 2007)

REMark - Revista Brasileira de Marketing, São Paulo, v. 12, n. 4, p. 153-182, out./dez. 2013. 
Tabela 2 - Escolha dos Critérios Relevantes

\begin{tabular}{|c|c|c|c|}
\hline & AHP & MAHP & ELECTRE \\
\hline \multicolumn{4}{|l|}{ ENTRADA DE DADOS (INPUT) } \\
\hline Utilização com decisões em vários níveis & $\operatorname{Sim}$ & Sim & Não \\
\hline Necessidade de processar dados antes que estes possam ser usados & Não & Sim & Sim \\
\hline Possibilidade de lidar com proble mas do tipo técnico & Sim & Sim & Sim \\
\hline Possibilidade de criar as escalas de julgamento de acordo como contexto & Não & Sim & Não \\
\hline \multicolumn{4}{|l|}{ SAÍDA DE DADOS (OUTPUT) } \\
\hline Proporciona ranking completo de alternativas & Sim & Sim & Não \\
\hline Proporciona soluções mu ito refinadas & Sim & Sim & Não \\
\hline Permite avaliação de coerência dos julgamentos & Sim & Não & Não \\
\hline \multicolumn{4}{|c|}{ INTERFACE TOMADOR DE DECIS ÃO VERS US MÉTODO } \\
\hline Disponibilidade de software sobre a estrutura do problema & Sim & Sim & Não \\
\hline Possibilita o aprendizado sobre a estrutura do problema & Sim & Sim & Não \\
\hline Facilidade para estruturar o proble ma & Alta & Média & Não \\
\hline Transparência no proces samento e no resultado & Alta & Baixa & Média \\
\hline
\end{tabular}

Fonte: Alves (2007, p.3)

A escolha do método AHP se deu como adequado para o desenvolvimento desta pesquisa, após analisar as informações contidas na Tabela 2 realizou-se um estudo detalhado na literatura disponível sobre tomada de decisão (MCDM). Sendo assim, foram considerados os seguintes aspectos relevantes para a escolha da ferramenta: consistência, lógica, transparência, facilidade de uso, quantidade de aplicações práticas e publicações científicas, tempo requeridas para o processo de análise e disponibilidade de software.

Através da análise realizada é possível considerar o AHP como o método mais recomendável para ser aplicado no ambiente empresarial por utilizar uma estratégia de descentralização do conhecimento e ser de fácil compreensão e aplicação e ainda possuir diversas aplicações práticas (ALVES, 2007). Segundo GUGLIELMENTTI, MARINS e SALOMON (2003), o AHP original foi considerado pelas pessoas consultadas, como o MCDM mais “amigável”, ou seja, tem seu entendimento mais fácil do que os dois outros métodos estudados. Principalmente, no que diz respeito à execução de aplicações práticas. De acordo com ALVES (2007) o AHP merece destaque, pois trabalha na divisão de problemas de decisão em nível hierárquico para obter uma melhor compreensão e a valiação.

Através dos critérios determinados foi possível chegar à conclusão que o método AHP seria o mais indicado para o desenvolvimento desta pesquisa. Pois ele tem vários atributos desejáveis para a realização do estudo proposto como: a) é um processo de decisão estruturado que pode ser documentado e repetido; b) é aplicável a situações que envolvem julgamentos subjetivos; c) utiliza tanto dados quantitativos como qualitativos; d) provê medidas de consistência

REMark - Revista Brasileira de Marketing, São Paulo, v. 12, n. 4, p. 153-182, out./dez. 2013. 
das preferências; e) há uma ampla documentação sobre suas aplicações práticas na literatura acadêmica; f) seu uso é apropriado para grupos de decisão (JIANYUAN (2010) e STEIGUER, DUBERSTEIN e LOPES (2010)).

\subsection{TRATAMENTO E ANÁLISE DOS DADOS}

Neste trabalho utilizou-se o software SUPERDECISIONS para o tratamento e análise dos dados do método AHP, o mesmo encontra-se disponível atra vés do site: www.superdecisions.com, que se torna possível modelar automaticamente as matrizes de comparação, de acordo com a hierarquia do problema de decisão que é implantada no programa pelo usuário, conforme Figura 3 do Manual Superdecisions (2003).

O software foi criado por uma equipe de profissionais orientados por SAATY, para desenvolver decisões em situações de grandes complexidades que utilizam o método AHP e o ANP para tomada de decisões e feedback. A ferramenta SUPERDECISIONS consiste em clusters de elementos (nós), e não elementos organizados em níveis. A menor hierarquia tem: cluster do objetivo contendo o objetivo (goal), o cluster dos critérios contendo os elementos dos critérios e o cluster de alternativas contendo seus elementos (alternativas).

De acordo com BOAS (2005) em uma análise teórica do AHP ao MAHP e ao ELECTRE, sinalizou-se com grande vantagem para a utilização do método AHP, a facilidade de obtenção de softwares para downloads em versão estudantil ou gratuita, além da simplicidade da interface tomador de decisão x método. Facilidades em estruturar o problema, a compreensão da estrutura do problema, a compreensão conceitual e detalhado do modelo e do algoritmo também foram lembrados pela autora a fim de justificar a preferência do AHP aos demais métodos.

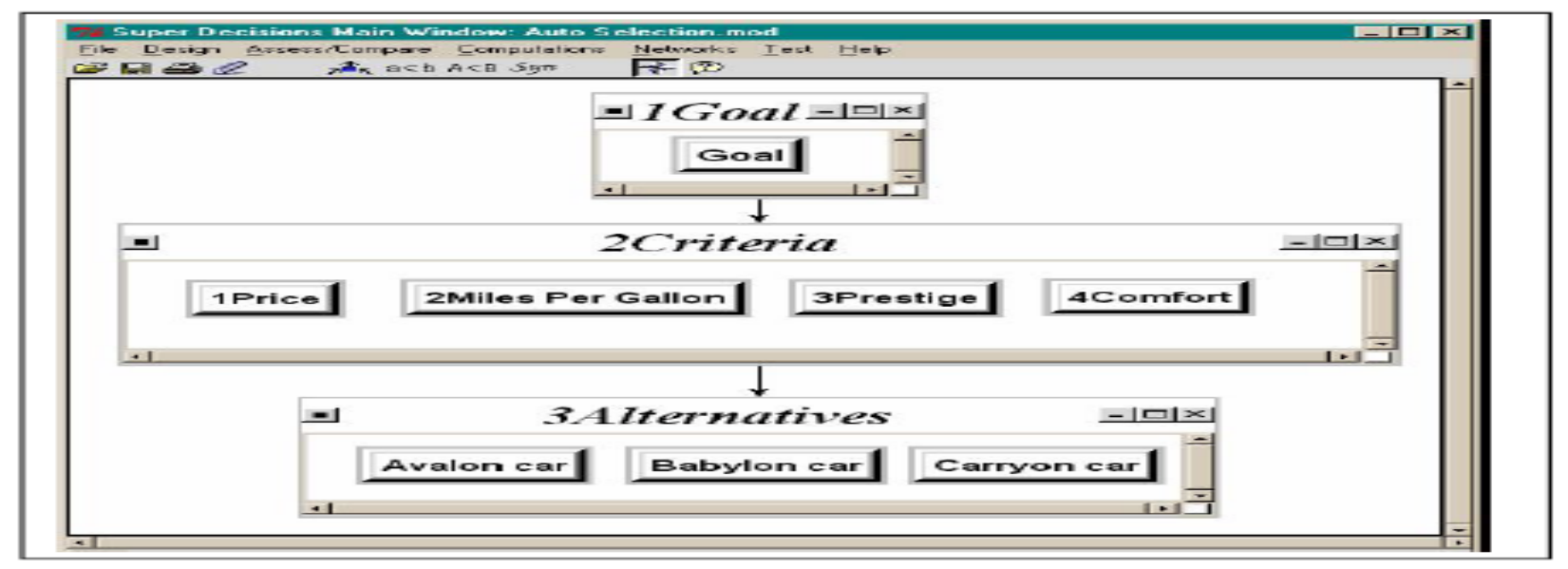

Figura 3 - Estrutura Hierárquica

Fonte: Manual Superdecisions (2003)

REMark - Revista Brasileira de Marketing, São Paulo, v. 12, n. 4, p. 153-182, out./dez. 2013. 
Antes da realização da análise dos resultados obtidos pelo software SUPERDECISIONS, faz-se necessário analisar pormenorizadamente as alternativas de decisão estudadas no presente trabalho. Em cada alternativa, gera-se um cenário diferente, com a possibilidade de manutenção ou desativação desse cenário.

SAATY (1991) define cenário como a representação de uma idéia particular de um assunto, sendo enfatizado como uma representação adequada de sua interação com fatores ambientais, sociais, políticos e tecnológicos e econômicos.

\section{RESULTADOS}

Nesta seção apresentam-se os resultados que tem por objetivo verificar qual o ponto critico que ocasiona o grande número de reclamações por parte dos clientes e conseqüentemente tende para ações judiciais, ocasionando com isso grandes despesas para as empresas do setor de telefonias moveis, conforme apresentado na Figura 4 do Resultado da Pesquisa.

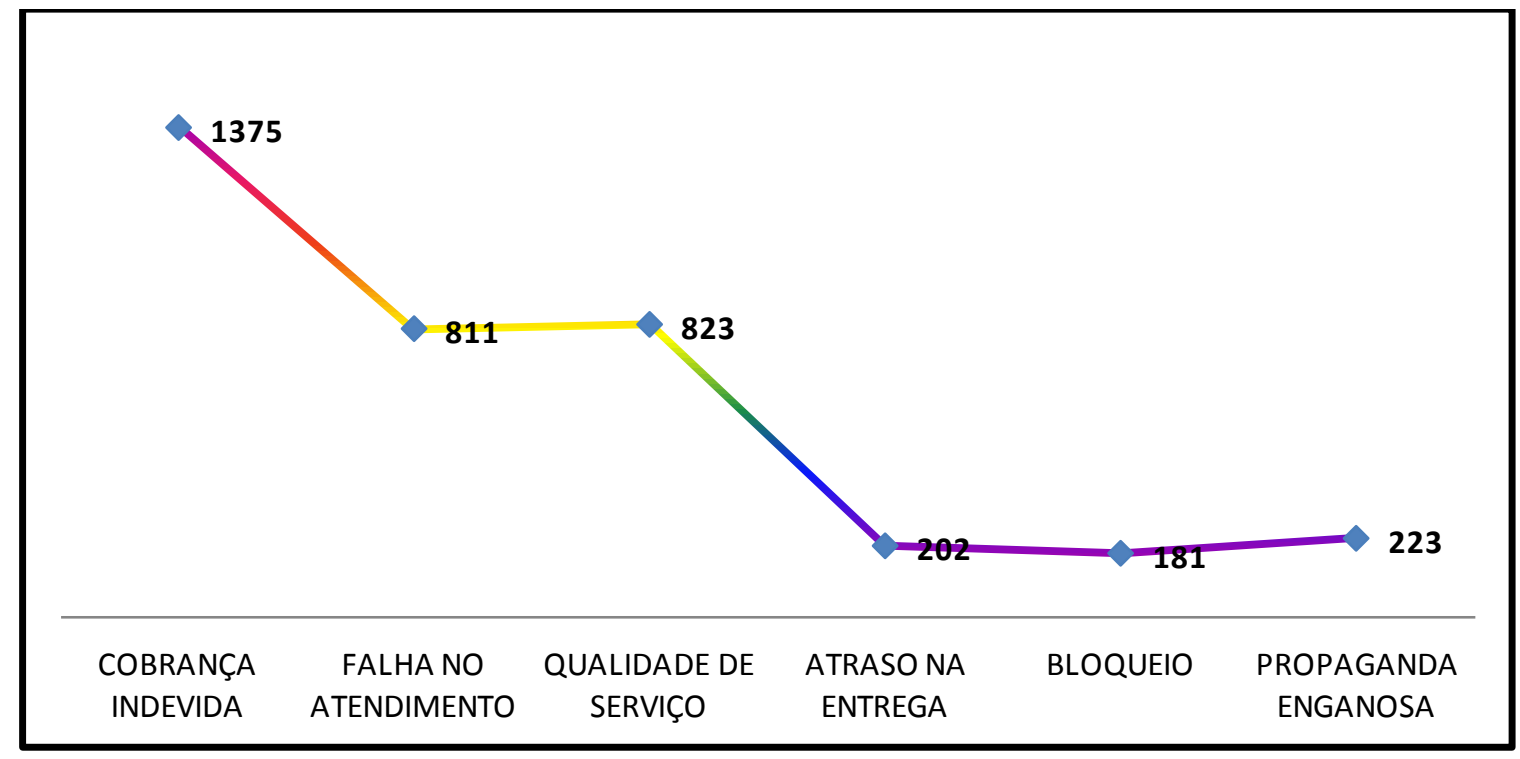

Figura 4 - Total de Reclamações.

Fonte: Resultado da Pesquisa

Para a conclusão dos resultados será levado em consideração itens que obtiverem: (1) menor desempenho; (2) maior importância; O resultado deste estudo se propõe a comprovar através de modelos matemáticos, qual a alternativa é a mais adequada a ser trabalhada em determinados períodos, os índices de menores e maiores importância serão obtidos através dos valores normalizados dos autovetores.

REMark - Revista Brasileira de Marketing, São Paulo, v. 12, n. 4, p. 153-182, out./dez. 2013. 
A lógica para obtenção dos resultados segue conforme é apresentado na Figura 5, onde ha $\mathrm{o}$ cliente $\mathrm{x}$ qualidade da prestação do serviço oferecido pela empresa. De acordo com PARASURAMAN, BERRY; ZEITHAML (1988), a qualidade percebida pelo serviço é resultado entre as comparações das percepções e expectativas do cliente.

Já HUBBERT (1994, p. 77) diz que a qualidade do serviço é a impressão do cliente sobre a relação superioridade/inferioridade da organização e dos seus serviços. Seria como a atitude resultante da comparação expectativas x percepção do serviço pelo cliente.

O objetivo lógico da Figura 5 do Resultado da Pesquisa é chegar ao ponto de relação entre Serviço Esperado e Serviço Percebido, conforme lógica abaixo:

a) Expectativas < percepções: a qualidade percebida é boa;

b) Expectativas = percepções: a qualidade percebida é aceitável;

c) Expectativas > percepções: a qualidade percebida é pobre;

Conhecendo as expectativas e problemas enfrentados pelos clientes a empresa poderá prestar um serviço adequado e/ou superar os problemas ocorridos.

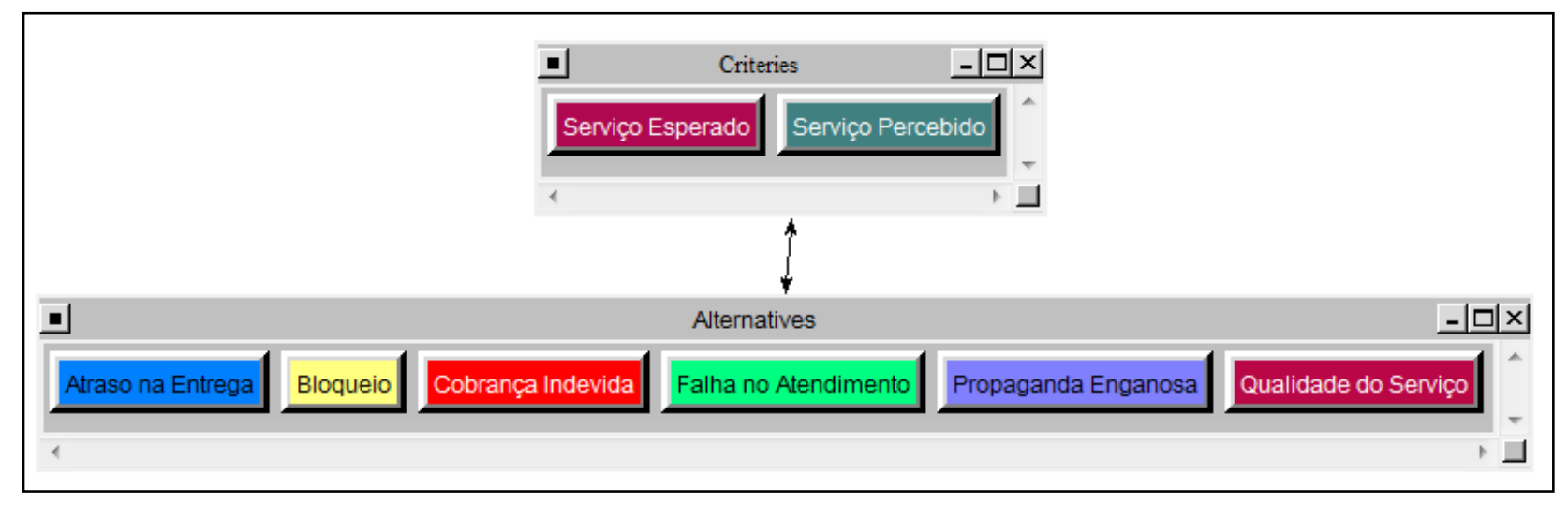

Figura 5 - Hierarquia Gerada a Partir do Software SUPERDECISIONS.

Fonte: Resultado da Pesquisa

Na Figura 5 foram definidos os critérios de acordo com PARASURAMAN, BERRY; ZEITHAML (1993) e as alternativas criadas com base segundo fontes do PROCON (2008) e RECLAMEAQUI (2010), o relacionamento entre as alternativas e critérios foi seguido conforme apresentado na Figura 5.

Através da Figura 6 do Resultado da Pesquisa é possível notar os valores determinados para julgamento e comparação entre cada critério determinado conforme notado nas Figuras 5, para que com isso possa finalizada a aplicação do método AHP.

REMark - Revista Brasileira de Marketing, São Paulo, v. 12, n. 4, p. 153-182, out./dez. 2013. 
Super Decisions Main Window: final,mod: Limit Matrix

$\square$

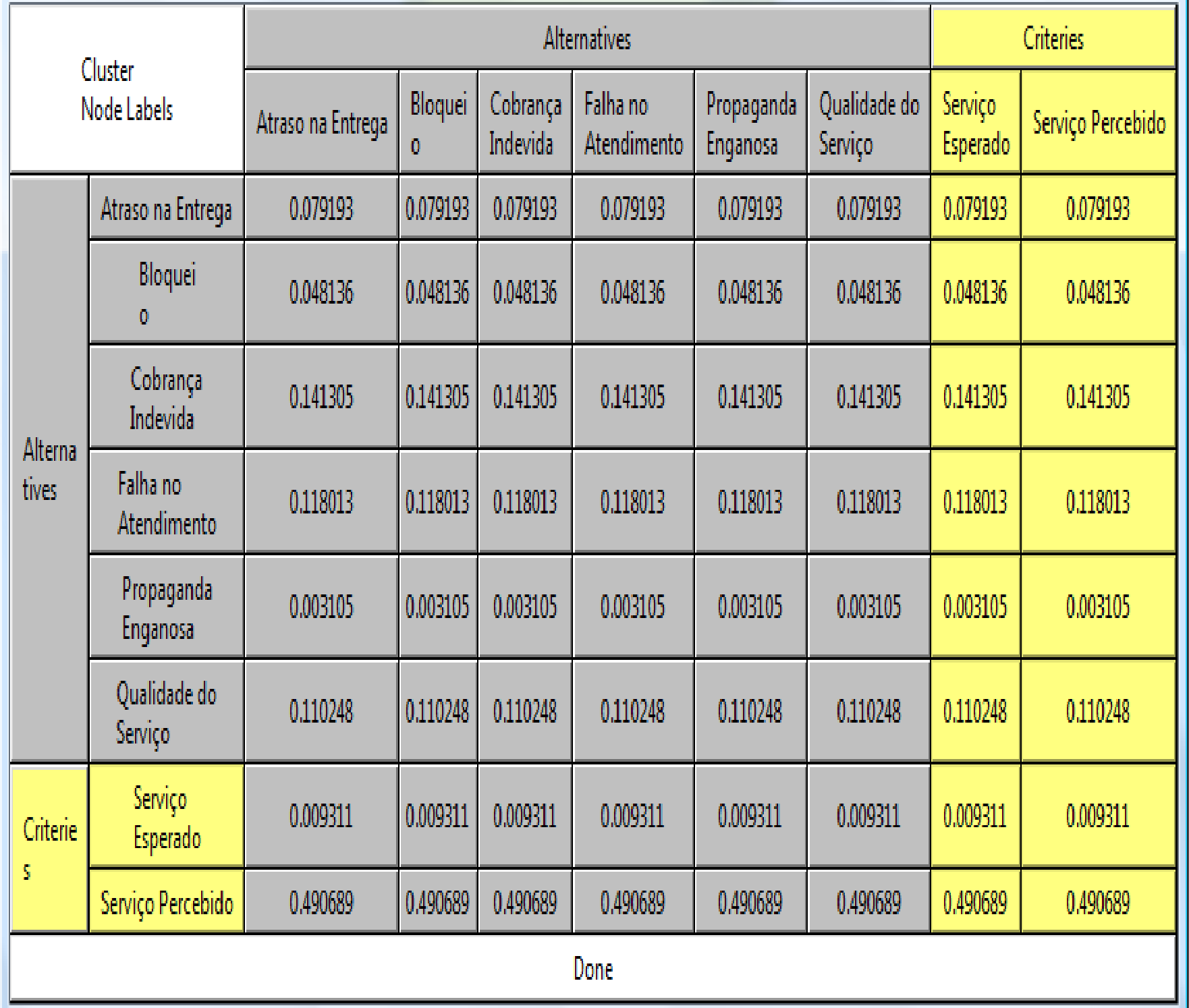

Figura 1 - Matriz Identificada

Fonte: Resultado da Pesquisa

Através do Gráfico 1 do Resultado da Pesquisa de prioridades é possível notar as prioridades a serem trabalhadas, nota-se um índice muito elevado na resultante Serviço Percebido em relação ao Serviço Esperado, através deste ponto percebesse a importância de uma maior atenção ao serviço o qual o cliente contrata, pois o mesmo não esta atendendo as expectativas do contratante.

REMark - Revista Brasileira de Marketing, São Paulo, v. 12, n. 4, p. 153-182, out./dez. 2013. 


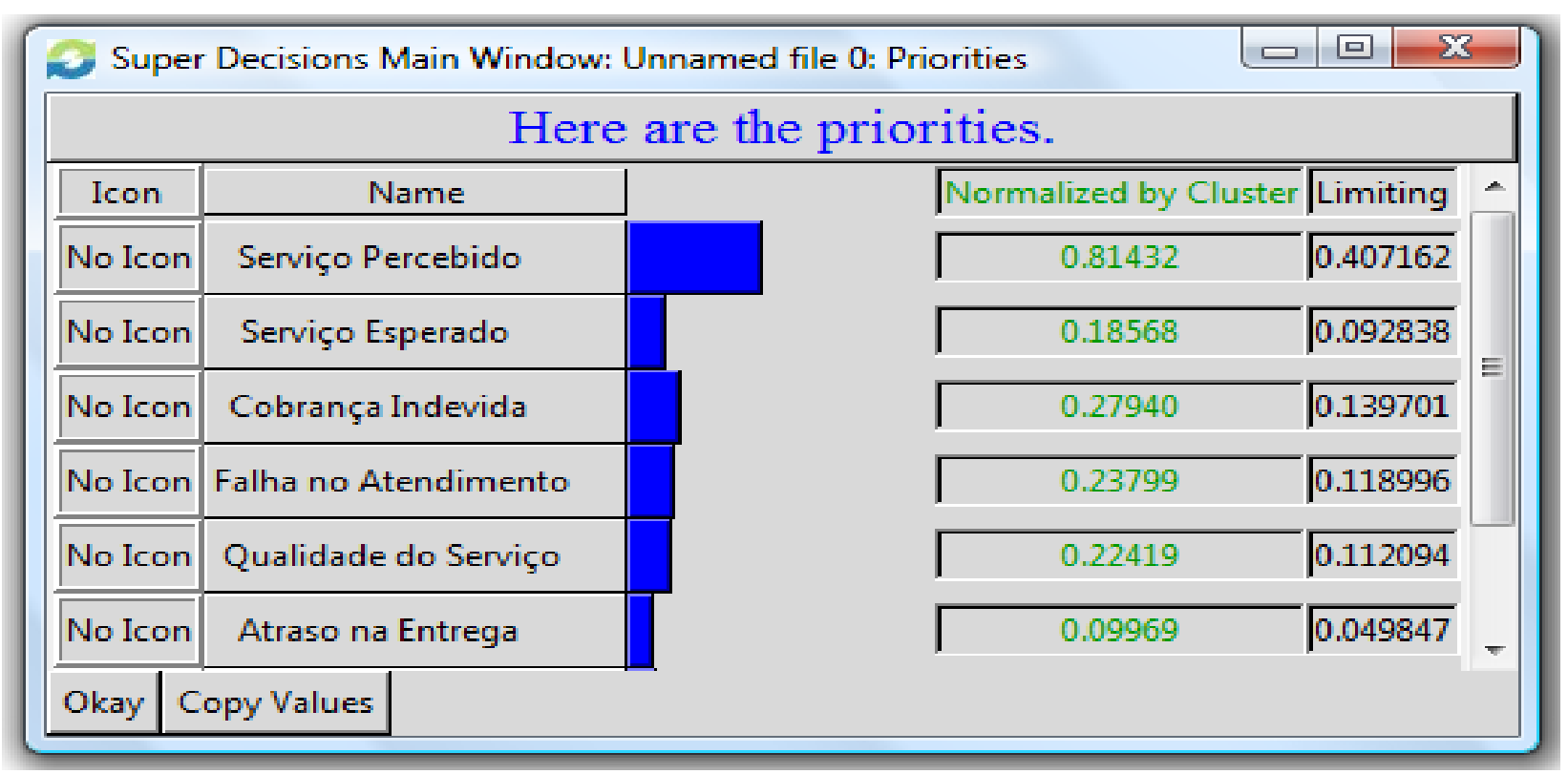

Gráfico 1 - Prioridades

Fonte: Resultado da Pesquisa

Através da aplicação do método AHP foi possível obter a importância e desempenho de cada critério a ser trabalhada, a importância e desempenho de cada critério pode ser notado através da Tabela 3 do Resultado da Pesquisa, junto com a análise de sensibilidade é possível visualizar qual critério deve ser trabalho e a partir de qual momento deve ser dada atenção ao critério e com isso conseguir obter um maior sucesso na organização.

Tabela 3 - Ranking das Alternativas

\begin{tabular}{|c|c|c|c|c|c|c|}
\hline ALTERNATIVAS & TOTAL & NORMAL & IDEAL & RANKING & IMPORTÂNCIA & DES EMPENHO \\
\hline Atraso na Entrega & 0.0498 & 0.0997 & 0.3568 & 5 & $9,97 \%$ & $90,03 \%$ \\
\hline Bloqueio & 0.0585 & 0.1170 & 0.4188 & 4 & $11,7 \%$ & $88,3 \%$ \\
\hline Cobrança Indevida & 0.1397 & 0.2794 & 1.0000 & 1 & $27,94 \%$ & $72,06 \%$ \\
\hline $\begin{array}{c}\text { Falha no } \\
\text { Atendimento }\end{array}$ & 0.1190 & 0.2380 & 0.8518 & 2 & $23,80 \%$ & $76,2 \%$ \\
\hline $\begin{array}{c}\text { Propaganda } \\
\text { Enganosa }\end{array}$ & 0.0208 & 0.0417 & 0.1492 & 6 & $4,17 \%$ & $95,83 \%$ \\
\hline $\begin{array}{c}\text { Qualidade do } \\
\text { Serviço }\end{array}$ & 0.1121 & 0.2242 & 0.8024 & 3 & $22,42 \%$ & $77,58 \%$ \\
\hline
\end{tabular}

Fonte: Resultado da Pesquisa

REMark - Revista Brasileira de Marketing, São Paulo, v. 12, n. 4, p. 153-182, out./dez. 2013. 
Percebe-se que pela realização da análise, apresentada no Gráfico 2 do Resultado da Pesquisa percebe-se que os itens de maior importância de acordo com seu grau apresentado são:

- Cobrança indevida;

- Falha no Atendimento;

- Qualidade do Serviço;

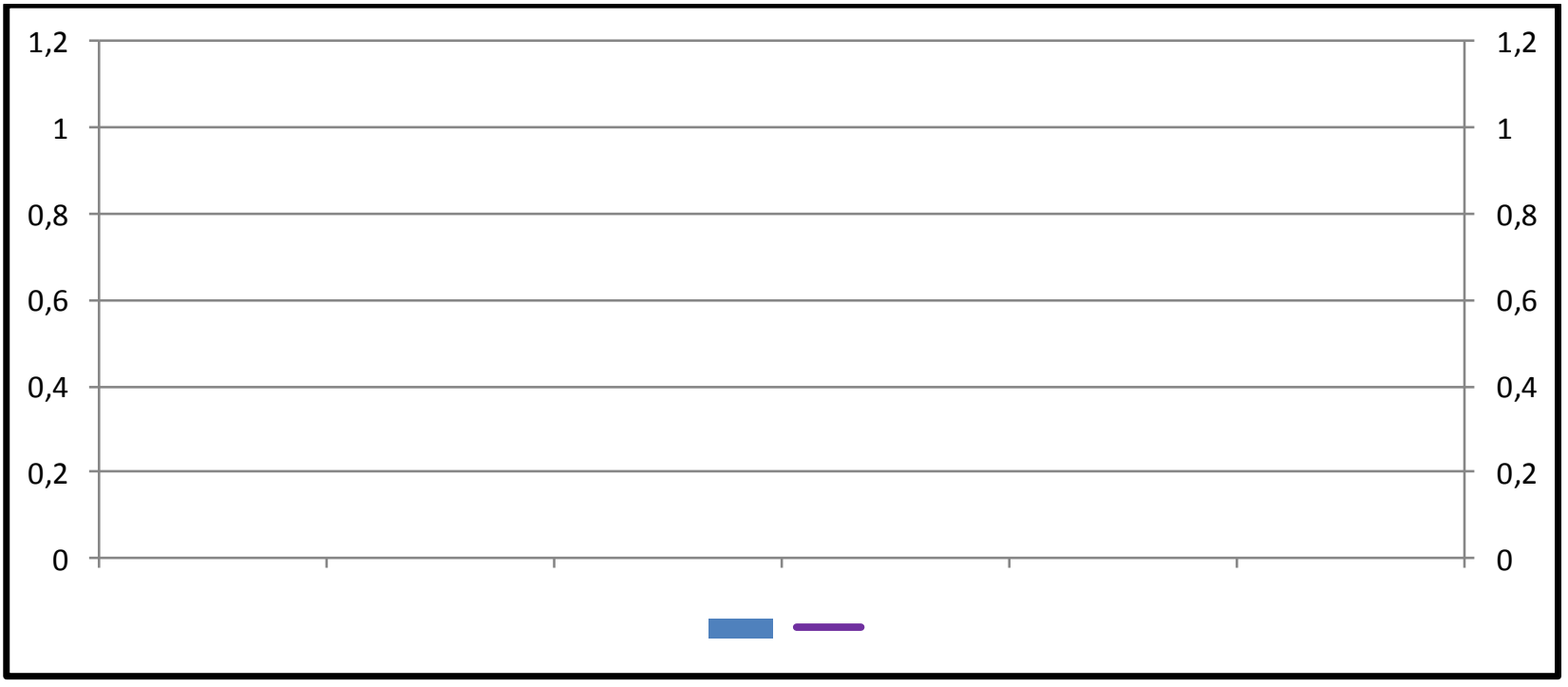

Gráfico 2 - Grau de Importância e Desempenho dos problemas

Fonte: Resultado da Pesquisa

Importante destacar que apesar do item Atraso na Entrega ter obtido um dos maiores desempenho e uma das menores importâncias para a empresa priorizar conforme apresentado na Tabela 3, destaca-se sua importância, pois durante análise realizada e levantamento dos dados conforme apresentado em anexo, foi possível notar que ocorreu um aumento significativo no número de reclamações sempre em períodos de lançamento de novos produtos.

Analisando o Gráfico 3 do Resultado da Pesquisa nota-se que o Atraso na Entrega é uma das maiores prioridades a serem tratadas pela empresa, pode-se notar isso através grande curvatura mostrada a qual tende o critério Atraso na Entrega, é possível identificar também que os outros 2 pontos principais a serem tratados são Cobrança Indevida e Falha no Atendimento. 


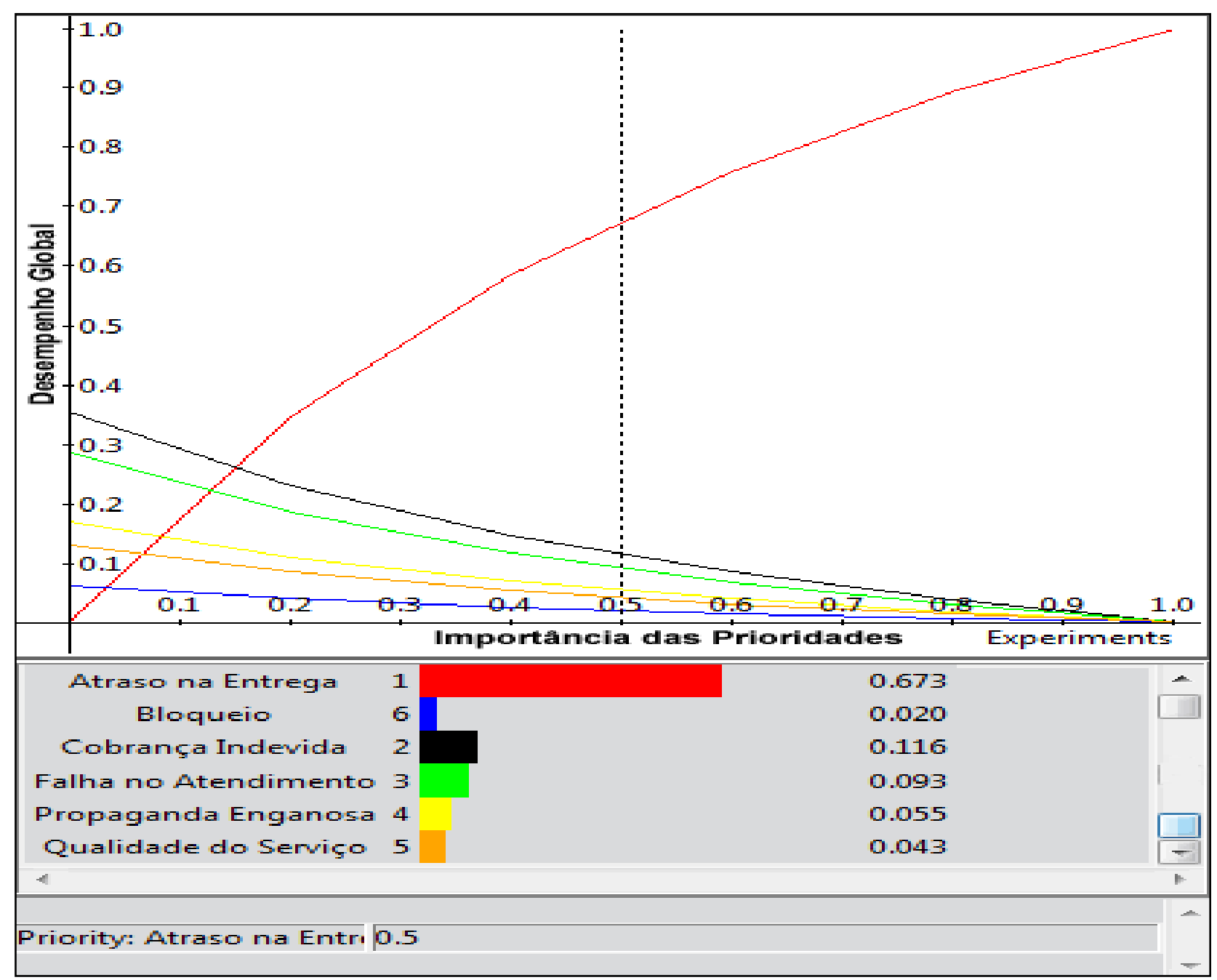

Gráfico 3 - Análise de Sensibilidade

Fonte: Resultado da Pesquisa

Visualizando o Gráfico 4 do Resultado da Pesquisa nota-se o momento exato onde o atraso na entrega deixa de ser a alternativa prioritária a ser tratada e tornando a alternativa Cobrança Indevida com item de maior prioritário para aquele instante. 


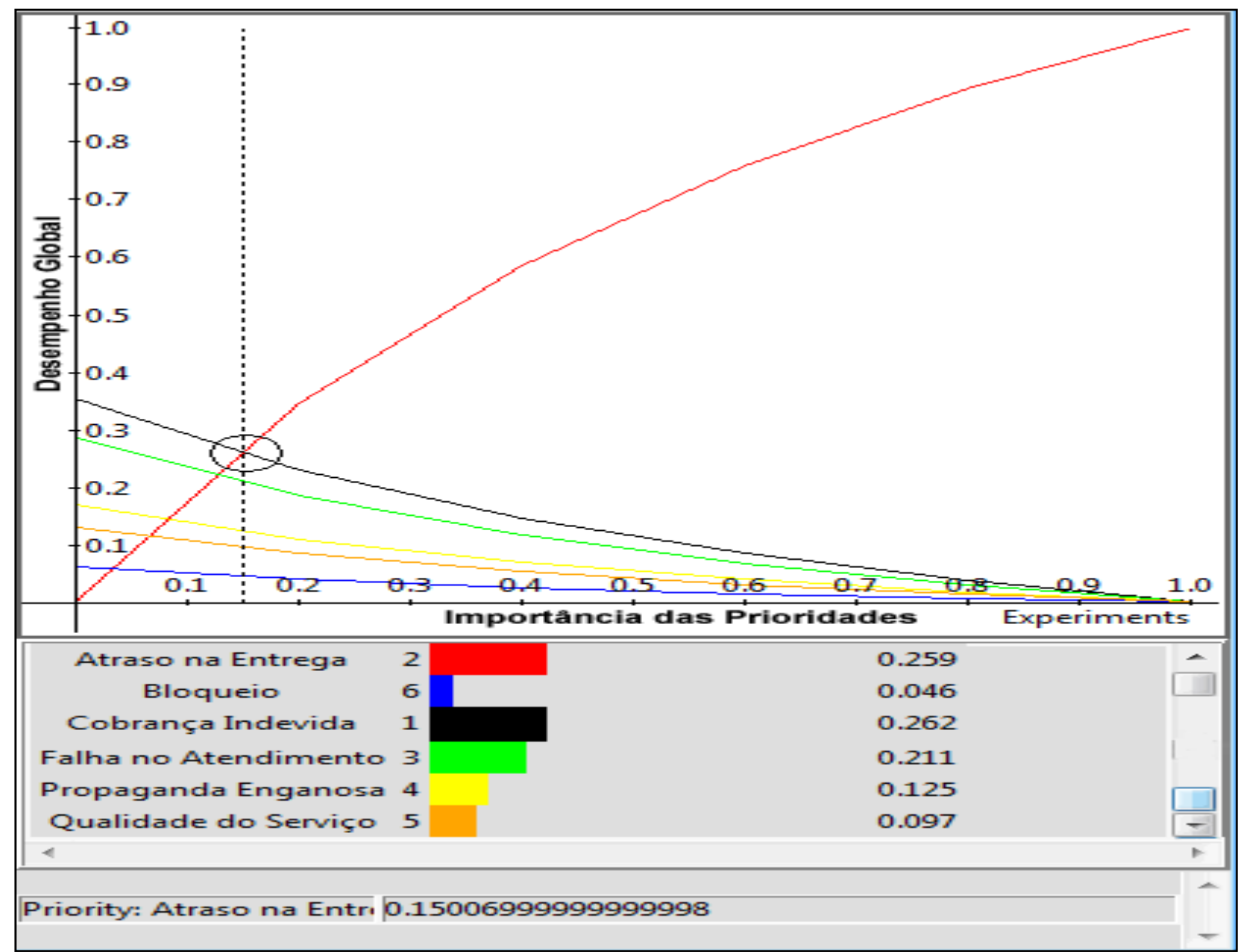

Gráfico 4 - Análise de Sensibilidade

Fonte: Resultado da Pesquisa

A análise de sensibilidade foi crucial para a conclusão deste trabalho, pois em um problema de análise de decisão, examina-se variações dos pay-off gerado pelas alternações dos valores das probabilidades das ocorrências dos eventos aleatórios.

Através da análise de sensibilidade foi possível concluir através dos resultados obtidos que durante o período de tempo analisado os itens Atraso na Entrega, Cobrança Indevida e Falha no Atendimento, são os itens principais a serem trabalhos pela empresa e em seguida os demais, porém nota-se que apesar do item Atraso na Entrega ter obtido um dos maiores desempenho e uma das menores importâncias para a empresa priorizar conforme apresentado na Tabela 3, destacamos sua importância, pois durante análise realizada e levantamento dos dados conforme apresentado em anexo, foi possível notar que ocorreu um aumento significativo no número de reclamações sempre em períodos de lançamento de novos produtos.

Deste nodo para que se possa vir a atingir os objetivos propostos no inicio do estudo, fazse necessário que a organização venha a solucionar os problemas existentes na seguinte ordem: 
a) Atraso na Entrega - a organização deverá buscar um aumento na sua efetividade operacional, de modo a reduzir a ocorrência de atrasos, garantindo assim maior consistência em seus prazos, acredita-se que a ocorrência deste feito esteja relacionada a fatores motivadores, quais devem ser avaliados, sendo estes:

- Falha no processo de previsão de demanda para o novo produto - faz-se necessário analisar e realizar ajustes ao processo de previsão de demanda deste novo produto ao longo de seu ciclo de vida para que possa adequar a produção ao seu atendimento;

- Desempenho operacional inferior - muitas vezes o planejado e o desempenho obtido não se apresentam compatíveis, deste modo a organização terá que analisar seu processo mensurando como esta a sua eficiência e eficácia operacional, buscando assim estabelecer planos para a sua adequação conforme a necessidade da demanda.

b) Cobrança Indevida - para o atendimento deste quesito, a organização deverá analisar seus processos internos, tanto a parte operacional qual envolve as pessoas, quanto à parte informatizada, relativo ao seu sistema de dados e operações, buscando assim identificar onde esta a raiz desta ocorrência, podendo a partir deste ponto estabelecer as medidas necessárias para sua solução, seja através da realização de treinamentos, ou alteração no fluxo de trabalho, dentre outras.

c) Falha no atendimento - este tipo de problema esta relacionado intimamente com o grau de treinamento e motivação do funcionário, sendo sua solução sob a responsabilidade do próprio colaborador, desde que existam procedimentos internos que possam ser aplicados na solução do problema do cliente, neste caso deve-se realizar um trabalho de treinamento e de motivação dos colaboradores, como também pode-se vir a adotar um sistema de remuneração por desempenho, qual o venha motivar a evoluir seus resultados. No caso das soluções que não se encontram nos procedimentos internos, estas devem ser revistas e incluídas nos procedimentos;

d) Qualidade de Serviço - a organização precisa realizar avaliação de seu sistema de qualidade, priorizando diagnosticar os níveis de qualidade e eficiência de seus serviços, atra vés de um sistema de indicadores qual possibilite a sua mensuração. Precisa-se aqui compreender qual o nível de qualidade esperado pelo consumidor e compará-lo ao nível fornecido, de forma a realizar as adequações necessárias.

Destaca-se como sugestão de grande importância para o alcance dos objetivos propostos a realização de uma análise de SWOT a fim de identificar seus pontos fortes, fraquezas, oportunidades e ameaças, seja interna ou externa para que possa melhorar o atual cenário da empresa.

REMark - Revista Brasileira de Marketing, São Paulo, v. 12, n. 4, p. 153-182, out./dez. 2013. 
Outra sugestão e a aplicação da cadeia de valor, a fim de verificar desde as relações com os fornecedores e ciclos de produção e de venda até o cliente final. A Cadeia de Valor fragmenta uma empresa em suas atividades de relevância estratégica para que seja possível compreender o comportamento dos custos e existências das fontes e potenciais de diferenciação. A execução das atividades estratégicas, seja de modo mais barato, ou melhor, faz com que a empresa possa ganhar vantagem competitiva. (QUINTELLA, MESCHESI e OLIVEIRA, 2003)

Sugere-se também a implantação do conjunto de boas praticas ITIL (Information Technology Infrastructure Library) para aplicação na infra-estrutura, operação e manutenção visando com isso à melhoria de um conjunto de processos e procedimentos gerenciais, com os quais a organização poderá fazer sua gestão tática e operacional em vista de alcançar o alinhamento estratégico com os negócios.

Pelos resultados obtidos atesta-se a aplicação do método, pois através do mesmo tornou-se possível a identificação dos critérios a serem tratados pela empresa e foi possível a constatação da eficiência de cada critério identificado, através da aplicação do método e de soluções aplicada nos problemas apontados tornará possível a redução dos níveis de ações judiciais sofrido pela empresa.

\section{CONCLUSÕES E RECOMENDAÇÕES}

Este trabalho teve por propósito analisar quais são os principais problemas que as companhias de telefonia móvel apresentam no Brasil, sendo estes os maiores motivadores de reclamações junto aos órgãos de proteção ao consumidor. Tais fatores prejudicam a imagem das empresas da empresa, reduzindo as sim sua competitividade frente à concorrência.

$\mathrm{O}$ estudo pormenorizado desses fatores teve como objetivo principal contextualizar o leitor, conduzindo-o ao entendimento sobre as peculiaridades das atividades do setor de telefonias, com o objetivo de mostrar as falhas envolvidas. Por tratar-se de um problema real, houve a necessidade de realizar uma revisão bibliográfica sobre as Telecomunicações especificamente voltadas às telefonias móveis, sugerindo a adoção de modelos multicriteriais para fazer face aos diversos aspectos envolvidos na fase decisória.

Pelo desenrolar do estudo optou-se pelo uso método AHP para tratar o problema que concentrou-se na hipótese da possibilidade de redução dos níveis de ações judiciais no setor de telefonia móvel. Sendo um dos grandes benefícios proporcionados por esta metodologia a realização da problemática, à sua possibilidade de estruturar hierarquicamente o problema,

REMark - Revista Brasileira de Marketing, São Paulo, v. 12, n. 4, p. 153-182, out./dez. 2013. 
permitindo um melhor entendimento do problema e elicitação de preferências na consideração dos vários aspectos qualitativos intrínsecos ao problema.

Pode-se comprovar a utilidade deste método na ordenação de prioridades dos alternativos ou planos de ação em projetos empresariais em que haja escassez ou impossibilidade de utilização ou de acesso a informações quantitativas do problema. Pode-se assim visualizar a sua viabilidade para aplicações em organizações em diferentes níveis de maturidade com relação à redução dos níveis de reclamações.

Através de cálculos automatizados, como multiplicação de matrizes, por exemplo, os programas eletrônicos facilitam a síntese dos resultados, verificação da coerência dos julgamentos e análise da sensibilidade. Na realização de matrizes de julgamentos é uma demonstração de como a utilização de planilhas eletrônicas deixam um pouco a desejar em comparação com softwares especializados.

Ao longo da análise foi possível constatar através do Gráfico 2, no qual o critério Cobranças Indevidas apresentou maior importância, pois este vem a ser responsável por mais de $27 \%$ das reclamações geradas, sendo seguido pelos problemas ocasionados pela falha no atendimento e qualidade de Serviços prestados, sendo por fim também considerado o critério Atraso na Entrega, pois apesar de ter sido considerado um dos itens de menores índices de prioridade, apenas 9,97\% de importância a ser tratado, o gestor deve atentar-se ao fato, pois a cada lançamento de produto no mercado o índice de reclamações aumenta de forma exorbitante, onde ocorre um aumento nos níveis de ações judiciais.

Identificadas as devidas importâncias relativas a cada um dos problemas, responsável por reclamações junto aos órgãos de proteção ao consumidor cabe agora às organizações de telefonia móvel analisar cada um destes problemas, identificando suas respectivas causas. Por meio desta análise será possível desenvolver planos operacionais para a solução destes problemas, focando assim seus esforços de forma mais eficiente, concentrando nos problemas de maior importância e impacto frente à imagem da empresa.

A pesquisa realizada apresenta contribuições em áreas distintas: apoio à Decisão, Desempenho Empresarial, Gestão de Qualidade e Análise Setorial. De modo geral, as principais contribuições desta pesquisa são relacionadas ao apoio à decisão. Normalmente, os textos a respeito deste tema, sejam livros ou artigos, apresentam os passos de um método ou de suas variações e discorrem sobre aplicações práticas. As contribuições desta pesquisa atuam diretamente no setor de telecomunicações, contribuindo na redução de custo e melhoria da qualidade dos serviços e imagem da empresa.

REMark - Revista Brasileira de Marketing, São Paulo, v. 12, n. 4, p. 153-182, out./dez. 2013. 
Ao se basear nos resultados obtidos na realização deste estudo, podem-se propor as seguintes continuidades de pesquisas:

- A aplicação do método proposto no setor de telefonia fixa e a análise dos resultados, como base para comparação e obtenção de conclusões em diferentes abordagens possíveis;

- Aplicação de lógica nebulosa (fuzzy ou ratings) para obtenção de uma flexibilidade ainda maior na obtenção dos julgamentos qualitativos;

- Desmembramentos dos critérios e alternativas, a fim de buscar as causas geradas para o acontecimento;

- Aplicação do método AHP em outras áreas do setor de telefonia móvel ou telecomunicações, como benefício às organizações;

- Análise do portfólio, no intuito de verificar investimentos e projetos tratados no setor e/ou empresa.

\section{REFERÊNCIAS}

ALVES, L. G. K.; NYKIEL, T. P.; BELDERRAIN, M. C. N.. Comparação Analítica entre Métodos de Apoio Multicritério à Decisão (AMD). Anais do 130 Encontro de Iniciação Científica e Pós-Graduação do ITA - XIII ENCITA / 2007. Instituto Tecnológico de Aeronáutica, São José dos Campos, SP, Brasil, Outubro, 01 a 04, 2007.

BOAS, C. L. V.. Modelo Multicritério de Apoio à Decisão Aplicado ao uso Múltiplo de Reservatórios: Estudo da Barragem do Ribeiro João Leite. Dissertação de Mestrado em Economia. Universidade de Brasília. Distrito Federal, 2006.

E-LIFE. Hábitos e Comportamento dos Usuários de Redes Sociais no Brasil 2013. Disponível em: < http://pt.slideshare.net/Elife2009/pesquisa-estudo-de-comportamento-e-hbitos-de-uso-dasredes-sociais-2013>. Acesso em 18/12/2013.

FRONTINI, Maria Alice Braga. Convergência Digital e a Telefonia Móvel: Implicações à Gestão Estratégica e à Inovação, 2008, 267f. Tese (Doutorado em Engenharia). Escola Politécnica da Universidade de São Paulo, 2008.

GOMES, K. G. A.. Um Método Multicritério para Localização de unidades Celulares de Intendência da FAB. Dissertação (Mestrado em Engenharia de Produção). Pontifícia Universidade Católica do Rio de Janeiro, 2009.

GUGLIELMETTI, F. R.; MARINS, F. A. S.; SALOMON, V. A. P. Comparação Teórica entre Métodos de Auxílio à Tomada de Decisão por Múltiplos Critérios. XXIII Encontro Nac. de Eng. de Produção - Ouro Preto, MG, Brasil, 21 a 24 de out de 2003.

REMark - Revista Brasileira de Marketing, São Paulo, v. 12, n. 4, p. 153-182, out./dez. 2013. 
HUBBERT, A. R. Encounter satisfaction versus overall satisfaction versus quality. In: RUST, R. T. e OLIVER, R. L. (Orgs.) Service quality: new directions in theory and practice. California: Sage Publications, 1994.

JIANYUAN, Y. Using Analytic Hierarchy Process as the auxiliary decision of computer integrated system for library management (CISLM). Nankai University, China. Disponível em: <http://web.simmons.edu/ chen/nit/NIT92/387-yan.htm>. Acesso em: 21 ago 2012.

MILlER, G. A.; O Número Mágico Sete, Mais ou Menos Dois: Alguns Limites Na Nossa Capacidade de Processar Informação. Psychological Review, 63, 81-97, 1956.

PARASURAMAN, A.; BERRY, L. L.; ZEITHAMLL, V. A. SERVQUAL: a multiple-item scale for measuring consumer perceptions of service quality. Journal of Retailing, New York, v. 64, n. 1, p.12-40, Spring 1988.

PARASURAMAN, A.; BERRY, L. L.; ZEITHAMLL, V. A. The Nature and Determinants of Customer Expectations of Service. Journal of the Academy of Marketing Science, Vol. 21, Number, 1, p. 1-12, 1993.

PEREIRA, Rodrigo de Araújo. Qual a Importância da Inteligência de Negócios e a Tomada de Decisão na Tecnologia da Informação. Monografia (Pós-Graduação em Gestão de Tecnologia da informação). Faculdade de Informática e Administração Paulista, FIAP, 2009.

PIOVESAN, Armando; TEMPORINI, Edméa R. Pesquisa Exploratória: procedimento metodológico para o estudo de fatores humanos no campo da saúde pública. In: Revista Da Saúde Publica, no. 29, ed. 4, 318-325, 1995.

PROCON-SP. Levantamento do Atendimento de Telefonia Fixa e Móvel em 2007 dos PROCONS Municipais. Equipe de Pesquisas - DEP - PROCON-SP, Março, 2008.

PROXXIMA. E.life analisa as redes sociais para 2013. Confira nove tendências relacionadas ao universo digital com base em estudos. Disponível em: < http://www.proxxima.com.br/proxxima/redes_sociais/noticia/2012/12/07/Elife-analisa-asredes-sociais-para-2013.html >. Acesso em 18/12/2013.

QUINTELLA, H. L. M. M.; MESCHESI, A.; OLIVEIRA, J. T.. Gestão Estratégica e Liderança. In Rev. Eletr. UFF. Relatórios de Pesquisa em Engenharia de Produção da UFF, Niterói Rio de Janeiro, 2003.

RAFAELI, L.; MÜLLER, C. J. Estruturação de um Índice Consolidade de Desempenho Utilizando o AHP. Gest. Prod., São Carlos, v. 14, n. 2, p. 363-377, maio-ago. 2007.

REVISTA PROCON-SP. São Paulo em Defesa do Consumidor. Fundação de Proteção e Defesa do Consumidor. Ed. Especial, 2010.

REMark - Revista Brasileira de Marketing, São Paulo, v. 12, n. 4, p. 153-182, out./dez. 2013. 
SAATY, T. Método de análise hierárquica. Tradução e revisão técnica Wainer da Silveira e Silva. São Paulo: Makron Books, 1991. 326p.

SAATY, T. L. Rank from comparisons and from ratings in the analytic hierarchy/netwok processes. European Journal of Operational Research, 168, 557-570, 2006.

SAATY, T. L. Decision making with the analytic hierarchy process. International Journal of Services Sciences, 1 (1), 83-97, 2008.

SAUNDERS, J. H. Comparison of Decision Accuracy in the Analytic Hierarchy Process and Point Allocation. Washington. Disponível em: $<$ http://www.johnsaunders.com/papers/ahpvpa/ahpvpa.htm>. Acesso em: Acesso em: 21 ago 2012.

SALOMON, V. P.; MONTEVECHI, J. A. B.; PAMPLONA, E. O.. Justificativas para Aplicação do Método de Análise Hierárquica. PAMPLONA, Edson de O. 19o ENEGEP. Rio de Janeiro, RJ, 1999.

SALOMON, V. A. P. \& MONTEVECHI, J. A. B. (2001), A compilation of comparisons on the analytic hierarchy process and others multiple criteria decision-making methods: some cases developed in Brazil, VI International Symposium on AHP, Proceedings, p. 413-420, Berna: Bern Universität.

SALOMON, V. A. P.; MARINS, F.; DUDUCH, M. Tomada de Decisões Múltiplas Aplicada à Seleção de Fornecedores de Equipamentos de uma Linha de Montagem em uma Fábrica de Autopeças. Pesquisa Operacional para o Desenvolvimento - v. 1. - n. 3 - pp. 208-217, 2009.

SALOMON, V. A. P. Contribuições para Validação de Tomada de Decisão com Múltiplos Critérios. Tese (Livre-Docência), f. 68. Universidade Estadual Paulista, Faculdade de Engenharia de Guaratinguetá, 2010.

SILVA, E. L. da.; MENEZES, E. M.. Metodologia da Pesquisa e Elaboração de Dissertação. 3a edição revisada e atualizada. Universidade Federal de Santa Catarina - Programa de PósGraduação em Engenharia de Produção - Laboratório de Ensino a Distância, 2001.

SILVA, N., B., X.; PAIVA, C. C. Comunicação Digital - Estudo do Site Reclame Aqui - Um Novo Meio Convergente Entre a Empresa e o Consumidor 2.0. III Simpósio Nacional ABCiber - Dias 16, 17 e 18 de Novembro de 2009 - ESPM/SP - Campus Prof. Francisco Gracioso.

SOUZA, V. J. Percepção dos Gerentes de Projetos quanto às Habilidades Necessárias para o Exercício da Profissão. 2003. 133 f. Dissertação (Mestrado em Administração) Universidade de Taubaté, Taubaté, 2003. 
SILVA, J. T. M.; CABRERA, P. A. L.; TEIXEIRA, L. A. A. Aplicação do Método de Análise Hierárquica no Processo de Tomada de Decisão: Um Estudo com o Empreendedor Agrícola da Região de Divino/MG. Revista Gestão e Planejamento, Ano 7, n ${ }^{\circ}$ 14, Salvador, Jul/Dez, 2006.

STEIGUER, J. E.; DUBERSTEIN, J.; LOPES, V. The Analytic Hierarchy Process as a Means for Integrated Watershed Management. Disponível em: $<$ http://www.tucson.ars.ag.gov/icrw/Proceedings/Steiguer.pdf $>$. Acesso em: 21 ago 2012.

ZAMBON, K. L.; CARNEIRO, A. A. F. M.; SILVA, A. N. R.; NEGRI, J. C.. Análise de Decisão Multicritério na Localização de Usinas Termoelétricas Utilizando SIG. Pesquisa Operacional, v.25, n.2, p.183-199, Maio a Agosto de 2005.

Data do recebimento do artigo: 26/06/2013

Data do aceite de publicação: 08/10/2013

REMark - Revista Brasileira de Marketing, São Paulo, v. 12, n. 4, p. 153-182, out./dez. 2013. 